\title{
Is early childhood care and education a good investment for Egypt? Estimates of educational impacts, costs, and benefits
}

Caroline Krafft

Follow this and additional works at: https://knowledgecommons.popcouncil.org/departments_sbsr-pgy

Part of the Demography, Population, and Ecology Commons, Early Childhood Education Commons, Family, Life Course, and Society Commons, Gender Equity in Education Commons, and the International Public Health Commons

How does access to this work benefit you? Let us know!

\section{Recommended Citation}

Krafft, Caroline. 2012. "Is early childhood care and education a good investment for Egypt? Estimates of educational impacts, costs, and benefits," Survey of Young People in Egypt Policy Brief no.3. Cairo:

Population Council. 


\section{Survey of Young People in Egypt Policy Brief Series}

\section{Is EARLY CHILDHOOd CARE AND EDUCATION}

\section{A GOOD INVESTMENT FOR EGYPT?}

Estimates of Educational

Impacts, Costs, and Benefits

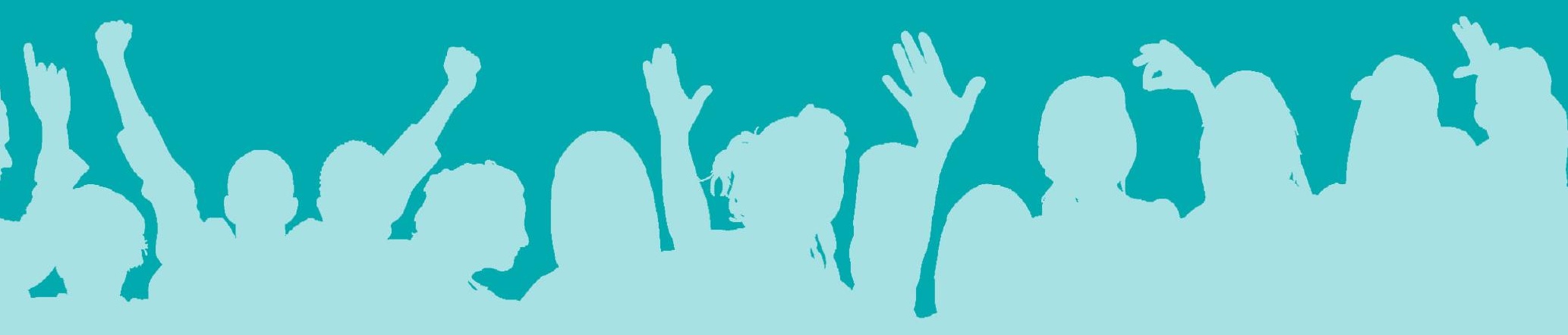

By Caroline Krafft

FORDFOUNDATION Working with Visionaries on the Frontlines of Social Change Worldwide
12 Population Council

Research that makes a difference 


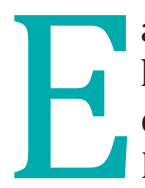
arly Childhood Care and Education (ECCE)kindergarten or nursery-is available to only some Egyptian children. Expanding ECCE should be a government priority, as ECCE is an excellent investment. ECCE improves a wide variety of educational outcomes, including educational attainment, drop out, repetition, test scores, and tracking into the more prestigious general secondary education as opposed to vocational education. Moreover, investing in ECCE will yield educational benefits that are greater than costs. Providing kindergarten to all Egyptian children, and particularly those from disadvantaged backgrounds, could be an important step toward greater equality, efficiency, and attainment in the education system.

\section{Key Messages}

- Early Childhood Care and Education (ECCE) significantly reduces drop out and repetition.

- ECCE leads to higher test scores.

- ECCE increases the probability of tracking into higher education.

- The benefits of ECCE are greater than its costs.

- Access to ECCE, such as free government kindergartens, should be expanded and should particularly target the poor.

\section{Why does Early Childhood Care and Education matter?}

Early childhood is the focus of many human development programs and policies because it is the time when persistent development gaps occur and interventions yield the greatest benefits (Heckman et al. 2006). Child care and education are two key early childhood interventions that have been proven to improve a broad variety of health, cognitive, behavioral, and educational outcomes. Because of these impacts, ECCE is considered a crucial part of meeting the Millennium Development Goals, as well as an important tool for development and poverty reduction (UNESCO 2006).

While ECCE can have important positive effects, individual programs show a wide variety of impacts (Nores and Barnett 2010). The quality of early childhood interventions and the country-specific context in which they are implemented can cause enormous variation in the impact of ECCE. In Egypt, there has been a shortage of evidence on the impact of ECCE. This brief presents new evidence showing that ECCE is an excellent investment for Egypt, with educational benefits alone outweighing costs.

\section{Methods}

The recommendations in this brief are based on an analysis of the 2009 Survey of Young People in Egypt (SYPE) ${ }^{1}$, a nationally representative survey of 15,000 Egyptian youth aged 10-29. The survey has a detailed educational section, including a question on whether the participant had attended kindergarten or nursery. The broad age range encompassed by SYPE, and the comprehensive nature of the education module, allow for a unique examination of the longterm benefits of ECCE.

The effect of ECCE, however, could not be estimated by simply comparing children with ECCE to those without. Such estimates are likely to have two serious problems. First, the data show that children who receive ECCE are more likely to be from wealthier and more educated families, and therefore would be more likely to have better educational outcomes regardless of ECCE. ${ }^{2}$ This association will lead to an overestimate of the effect of ECCE. Since many of these characteristics occur on the family level, this study compares siblings within a family, one of whom attended ECCE and one of whom did not, in order to accurately estimate the effect of ECCE. The estimates of ECCE effects are based on a comparison of 2,478 such siblings.

The second problem is that many of the youth in the dataset are still in school. They will likely complete additional years of schooling, but it is not possible to observe these future years of schooling in the data. Estimating the impact of ECCE on years of schooling without accounting for this fact would result in underestimating ECCE's impact. Survival analysis (time-to-event) methods are therefore used to model the probability of students leaving school. ${ }^{3}$ The analysis is also careful to not include children who never entered school in these comparisonsthis would falsely attribute to ECCE the intention to educate children at all.

\section{Early Childhood Care and Education in Egypt}

Early Childhood Care and Education in Egypt has two main forms: kindergarten and nursery. Kindergartens are one to two years of pre-primary classes for children aged four to six. There are teachers and

\footnotetext{
${ }^{1}$ SYPE was conducted in cooperation with the Egyptian Cabinet's Information and Decision Support Center (IDSC) and funded by multiple donors.

${ }^{2}$ This is astatistical approachcalled "fixed effects" thatcan identify the causal effect of ECCE on educational outcomes.

${ }^{3}$ These methods account for the "right censoring" of students who are currently in school.
} 
formal curricula. Kindergartens are under the oversight of the Ministry of Education. Approximately half of kindergartens are government run. The remainder are run by NGOs, religious schools, employers, or individuals. Nurseries are supposed to provide care for children under the age of four, but nearly $40 \%$ of children in nursery are in fact age four to six because of a shortage of kindergarten space. Less than a third of nursery services are public, under the Ministry of Social Solidarity. The remainder are run by NGOs or are privately provided (UNDP 2008).

Figure 1: ECCE attendance by gender and birth cohort

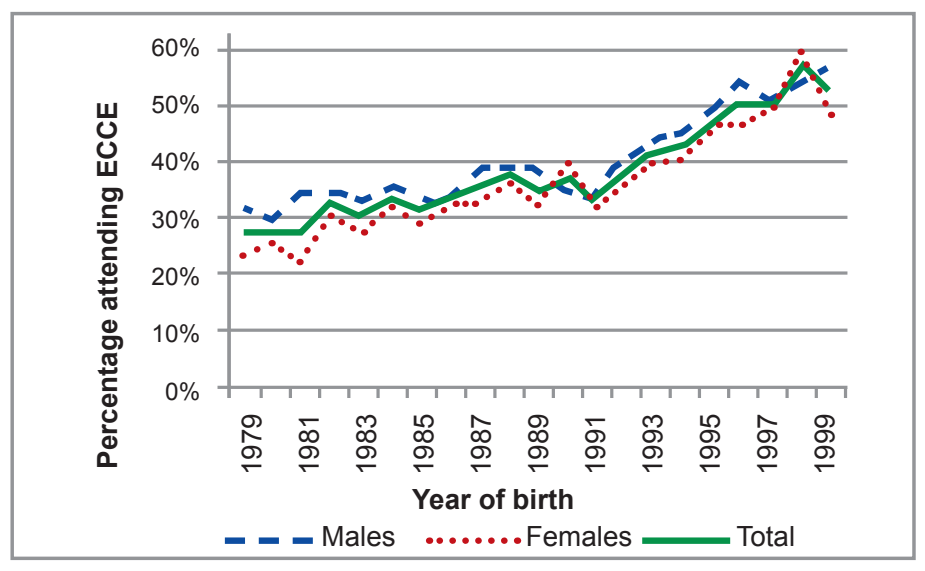

Use of nurseries and kindergartens has been increasing over time. Figure 1 shows the trend in children attending nursery or kindergarten (ECCE) by gender. Less than $30 \%$ of children born in 1980 attended ECCE. More than $50 \%$ of children born in 1999 attended ECCE. Historically, there has been a gender gap in ECCE attendance in Egypt, with males more likely to attend than females. This gender gap, like the gender gap in school entry, has been closing over time. The closing gender gap and increasing use of ECCE are promising trends, but many children still remain without ECCE services or with access to only low-quality ECCE (UNDP 2008).

\section{Early Childhood Care and Education improves a wide variety of educational outcomes}

ECCE has an impact on a variety of educational outcomes. One of the most important is educational attainmentthe number of years of schooling achieved by youth. Figure 2 shows the proportion of youth remaining in school beyond the end of each year (the "survival" of youth within the schooling system), by whether or not the youth attended ECCE (nursery or kindergarten). This figure estimates the effect of ECCE based on the sample of youth in households where at least one sibling attended ECCE and at least one sibling did not-the within-family sample. These estimates include controls for individual characteristics, such as gender, that differ between siblings. ${ }^{4}$

Figure 2: Proportion of youth remaining in school by ECCE

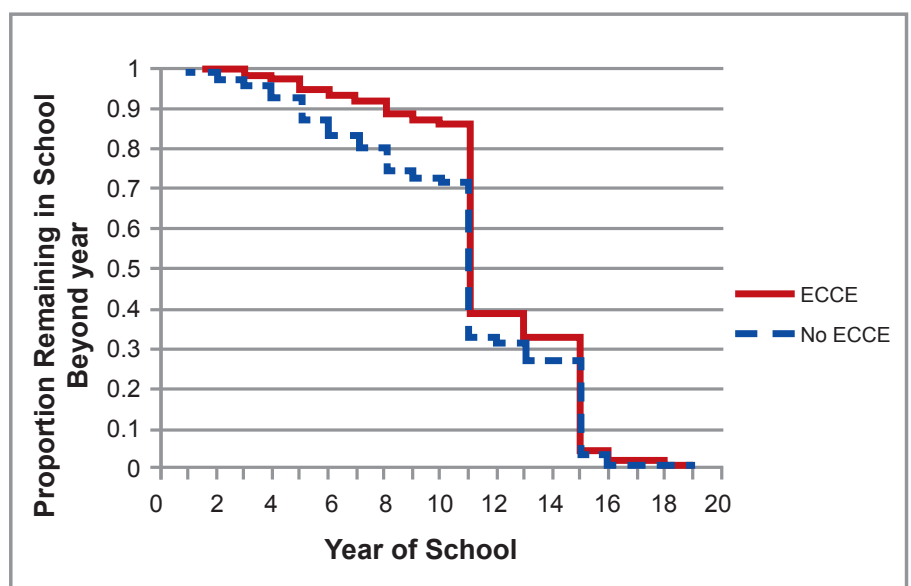

As students progress through primary (here counted as five years), youth with ECCE are more likely to remain in school than their siblings who did not attend ECCE. Youth with ECCE are more likely to continue from primary to preparatory, from preparatory to secondary, and from secondary to higher education.

The underlying differences in the probability of leaving school as a result of ECCE are statistically significantly during primary and at the end of both primary and preparatory school, when many students leave. Estimates indicate that the probability of leaving school at the end of primary and preparatory is more than halved with ECCE.

\section{Attending ECCE leads to 1.09 additional years of school.}

The changes in the probability of leaving school can be used to calculate how many additional years of school a student achieves if he or she attends ECCE. Attending ECCE leads to 1.09 additional years of school on average. These changes in schooling would have a dramatic effect on educational attainment in Egypt. Figure 3 presents the change in educational attainment for all youth entering school that would result from universal ECCE as opposed to no ECCE. With ECCE, 8.1\% more youth who enter school would leave school with a secondary education and $4.5 \%$ more youth would attain a university education. Likewise, there would be $11.4 \%$ fewer youth attaining less than a preparatory education. Figure 3 demonstrates both the increased educational attainment of youth with ECCE, and the increased educational capacity

${ }^{4}$ For complete details on model specifcation and control variables see Krafft (2011). 
that will be needed. Additional capacity would be particularly necessary during preparatory and secondary years, with some modest additional capacity in both primary and university years.

Figure 3: Changes in attainment with ECCE

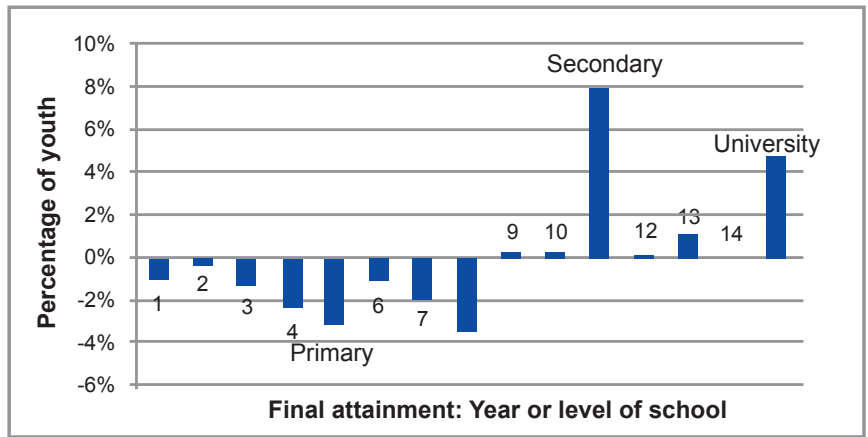

Increased educational attainment and the commensurate decrease in drop out are not ECCE's only potential benefits. ECCE also has an important impact on grade repetition, test scores, and tracking into higher education. Access to higher education is particularly important because it essentially determines access to formal government jobs and ability to contribute to modern enterprises and a knowledge-driven economy. Of the youth entering secondary school, $40.2 \%$ are on the general secondary (university-bound) track, with the remainder attending vocational secondary, which is usually terminal. ECCE early in life increases by 7.8 percentage points the probability that a young person will track into general secondary and university.

Grade repetition is a pervasive problem in Egypt. Repeating grades is expensive because it means that it takes more time and resources for a child to attain the same level of education. Repetition is also a symptom of low educational quality and poor learning outcomes. As Figure 4 shows, 7.6\% of children who did not attend ECCE but did enter primary repeated at least one grade during primary, and $14.2 \%$ of children who did not attend ECCE but did enter preparatory repeated at least one grade in preparatory. The within-family estimates indicate that attending ECCE significantly decreases primary repetition by 3.4 percentage points (almost half) and preparatory repetition by 3.7 percentage points (about a quarter). ECCE does not have a significant effect on secondary repetition.
Figure 4: Grade repetition by ECCE

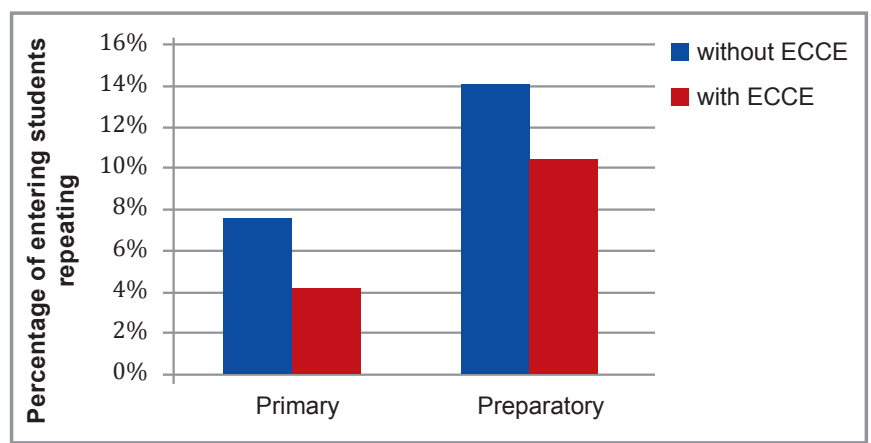

Test scores are quite important in Egypt because children have to take standardized exams at the end of each level of school and their exam scores determine secondary tracking and access to university. Test scores can also act as an approximation of cognitive and learning outcomes. Scores are out of 100 . The average primary score reported by SYPE respondents who did not attend ECCE is 77.3 , and the average preparatory score is 70.8. ECCE predicts higher test scores; a significant 1.9 points higher in primary, and a marginally insignificant 2.2 in preparatory.

The sizable impact of ECCE on a number of different educational outcomes indicates that expanding ECCE would be a powerful strategy for addressing a variety of Egypt's educational challenges.

\section{The benefits of Early Childhood Care and Education are greater than its costs}

While it is clear that ECCE improves educational outcomes, expanding the provision of ECCE has substantial costs. As well as the costs of ECCE itself, additional years of schooling create other costs. Youth who attend school when they could be working face opportunity costs: the loss of wages they would have obtained if they had not been in school. This brief includes a cost-benefit analysis (CBA) of ECCE to indicate whether the monetized benefits of ECCE outweigh its costs. In the CBA, costs and benefits must be discounted in order to compare the costs and benefits of an investment in ECCE with simply allowing the same money to accrue interest. This analysis uses a standard 3\% discount rate.

The ratio of benefits to costs for ECCE is 1.31.

The CBA solely examines the benefits of increased educational attainment-mediated through higher 
wages 5 - and decreased repetition. These benefits are compared over time to the costs of ECCE itself (based on the costs of expanding kindergarten, including capital costs), the costs of additional schooling, and the opportunity cost of lost wages. The ratio of benefits to costs for ECCE is 1.31. This means that every dollar invested in ECCE will return 1.31 dollars. Benefit-cost ratios greater than 1 , such as that for ECCE, indicate worthwhile investments.

This cost-benefit analysis is an extremely conservative estimate of likely ECCE benefits because it focuses solely on increased educational attainment and decreased repetition. International literature suggests a multitude of other benefits from ECCE, including health, nutritional, and behavioral improvements (Nores and Barnett 2010), decreased criminality, decreased use of social services (Reynolds et al. 2011), increased female labor-force participation, and a day-care benefit (World Bank 2010). Since the educational benefits of ECCE more than justify its costs, these additional likely benefits make ECCE a crucial investment.

\section{Further expansion of Early Childhood Care and Education needed}

Egypt is approaching universal primary enrollment, getting everyone into school. The next educational challenge is keeping youth in school and ensuring that school years deliver a high-quality education that will provide bright futures and economic opportunities. Egypt faces steep challenges in delivering this type of quality education. The TIMSS (Trends in International Mathematics and Science Study) found in 2007 that on average eighth-grade Egyptian students had quite low achievement, with only the most basic knowledge of whole numbers, decimals, and basic graphs (UNESCO 2010). High repetition rates are also symptomatic of low-quality education. Additionally, the quality and quantity of education that youth attain, especially higher education, is highly determined by their backgrounds, especially their parents' wealth and education, providing little opportunity for the majority of Egyptian youth (Assaad and Krafft 2010).

This analysis shows that Early Childhood Care and Education can significantly and substantially enhance the Egyptian educational system. ECCE has long-term benefits that extend well beyond primary school. It

\footnotetext{
${ }^{5}$ Based on estimates in Salehi-Isfahani, Tulani and Assaad 2009. See Krafft 2011 for further details on CBA estimation.
}

can increase educational attainment, improve test scores, reduce repetition, and improve tracking into higher education. While the Egyptian government has expressed its intention of expanding access to early childhood education to $60 \%$ of children by the year 2015, both this target and timetable should be moved up. Currently, Egypt devotes a disproportionate share of its educational spending to higher education, which is utilized primarily by the wealthiest Egyptians. Some of these resources should be shifted to ECCE, which offers substantial benefits to the entire population.

The government should rapidly expand access to free ECCE and should target children from disadvantaged areas.

Increased government provision of free, high-quality kindergarten and nursery programs to children from disadvantaged backgrounds is particularly important. Providing high-quality ECCE primarily to families that would purchase it anyway is a poor use of government resources. Unfortunately, this is the current situation in Egypt. Current provision of kindergartens is such that the poorest governorates also have the lowest kindergarten availability and enrollment. This makes poorer children entering school doubly disadvantaged compared with their wealthier peers, due to their poverty, and also due to their lack of access to kindergarten and the important benefits of ECCE.

Cost is a major barrier to private ECCE enrollment, and lower cost programs are generally lower quality, making government provision crucial to providing ECCE in poorer areas. Targeting ECCE expansion based on income or wealth can be administratively burdensome; however, since poverty in Egypt is closely connected to residence and geography, geographic targeting offers a costless method for prioritizing kindergarten expansion. Government provision is also important because many of the likely benefits of ECCE are public benefits, such as reduced crime or improved child health. One study in the United States found that public benefits were four times private benefits such as wages (Reynolds et al. 2011).

ECCE can make important contributions to the educational success and life opportunities of Egyptian youth. Investing in ECCE will yield educational benefits that are greater than ECCE costs. Therefore, expanding kindergarten access to all Egyptian youth would be an excellent policy for the Egyptian government to pursue. 


\section{References}

Assaad, R., and C. Krafft. 2010. The Social Background and Attitudes of Higher Education Students and Graduates in Egypt. Report prepared for the Social Science Research Council Project on University Governance and Autonomy in the Changing Landscape of Higher Education in the Arab World. December 2010 (mimeo).

Heckman et al. 2006. "Skill formation and the economics of investing in disadvantaged children," Science. 312: 1900-1902.

Krafft, C. 2011. "Is Early Childhood Care and Education a good investment for Egypt? Estimates of educational impacts, costs, and benefits." Unpublished master's thesis.

Nores, M., and W. S. Barnett. 2010. "Benefits of early childhood interventions across the world: (Under) Investing in the very young," Economics of Education Review. 29: 271-282.

Reynolds, A., J. Temple, B. White, and S.-R. Ou. 2011. "Age 26 cost-benefit analysis of the child-parent center early education program, Child Development. 82(1): 379-404.

Salehi-Isfahani, D., I. Tulani, and R. Assaad. 2009. “A comparative study of returns to education of urban men in Egypt, Iran, and Turkey." Middle East Development Journal. 1(2): 145-187.

UNDP. 2008. Egypt Human Development Report. UNDP.

UNESCO. 2006. EFA Global Monitoring Report: Strong foundations: Early childhood care and education. Paris: UNESCO.

UNESCO. 2010. EFA Global Monitoring Report: Reaching the Marginalized. Paris: UNESCO.

World Bank. 2010. Turkey: Expanding Opportunities for the Next Generation. Washington, DC: World Bank.

The Population Council confronts critical health and development issues-from stopping the spread of HIV to improving reproductive health and ensuring that young people lead full and productive lives. Through biomedical, social science, and public health research in 50 countries, we work with our partners to deliver solutions that lead to more effective policies, programs, and technologies that improve lives around the world. Established in 1952 and headquartered in New York, the Council is a nongovernmental, nonprofit organization governed by an international board of trustees.

\section{www.popcouncil.org}

